\title{
دور برامج الجرافيك في تفعيل وإدراك الواقع الافتراضي للتصميمات الطباعية
}

\author{
د / حاتم محمد حمدي محمد عبد الحميد \\ مدرس الطباعة بقسم التربية الفنية \\ كلية التربية النوعية - جامعة دمياط
}

المؤتمر الدولى الأول لكلية التربية النوعية - جامعة الاسكندرية

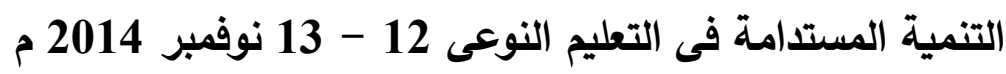




\title{
دور برامج الجرافيك في تفعيل وإدرإك الواقع الافتراضي
}

للتصميمات الطباعية

د / حاتم محمد حمدي محمد عبد الحميد

مدرس الطباعة بقسم التزبية الفنية

كلية التربية النوعية - جامعة دمياط لتربية الفية

ملخص البحث

يهدف البحث إلى الاستفادة من الإمكانات الفنية لبرامج الجرافيك وخاصة برنامج (3D Max)

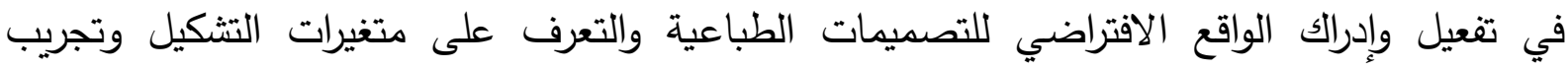
احتمالات لتطبيق التصورات والتي يمكن أن تسهم في تجويد عمليات التصميم الطباعي وتحسين شكل فئل فئرات الحياة وتغير مفهومها في ضوء متطلبات العصر وفلسفته .

The Role of Graphics Programs in the Activation of Virtual Reality and Realize Designs for Printing

\begin{abstract}
:
The research aims to take advantage of the technical capabilities of the graphics programs and especially (3D Max) program in the activation and realization of virtual reality to printing designs and identify the composition variables and experimenting the possibilities of the application of conceptions, which can contribute to improve of graphic design processes and improving the life style and change its concept in the light of the day requirements and it's philosophy.
\end{abstract}

Hatem Mohamed Hamdy Mohamed Abd El-Hameed Lecturer of Textile Printing - Art Education Department Faculty of Specific Education - Damietta University 


\section{دور برامج الجرافيك في تفعيل وإدرالك الواقع الافتراضي}

\section{للتصميمات الطباعية}

| د الد / حاتم محمد حمدي محمد عبد الحميد

مدرس الطباعة بقسم التربية الفنية التئية

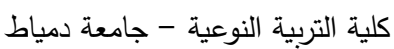

ينطلق التصميم الطباعي من العديد من المحاور التفاعلية التي تحقق أهدافه ، حيث تكمن أهم

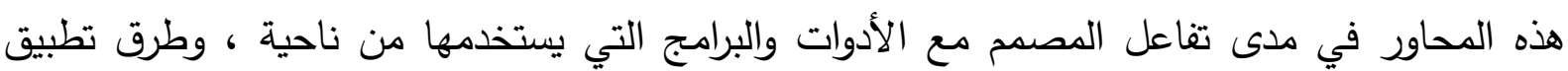
التصديمات وتوظيفها ، وتضافر هذه الدحاور وتفاعلها وتفعيلها تعطي انطباعا لا لبس فيه بددى التكامل التيل بين التصميم والتوظيف وصولاً لأعلى مستوياته . وبواسطة برامج الجرافيك يجري تمثيل التصميمات تمثيلا مبتكرًا ومركرًا ، بما يحيلها إلي صورة مرئية معبرة تؤثر من خلالها هذه التقنيات في الحياة وتوفر للمصمين وعيا وتفهما لما سيكون عليه

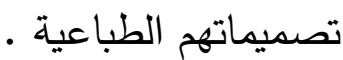
ويرتكز البحث على الاستفادة من الإمكانات الفنية لبرامج الجرافيك وتوظيفها في تطبيق

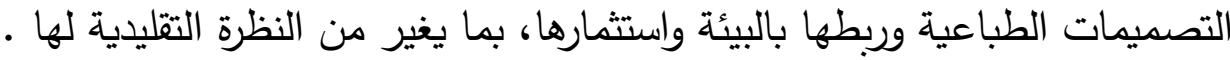

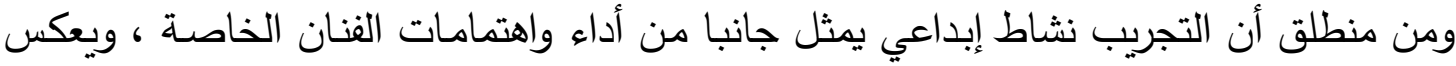
أسلوبه ، يسعى الباحث للتجريب بهدف التعرف على متغيرات التشكيل واستحداث حلول لتوظيف العمل التحل الطباعي وتغير مفهومه في ضوء منطلبات العصر وفلسفته . ويتصور الباحث أن غياب الواقع الافتراضي لتطبيق التصميمات الطباعية التي تتيحه برامج وفئه

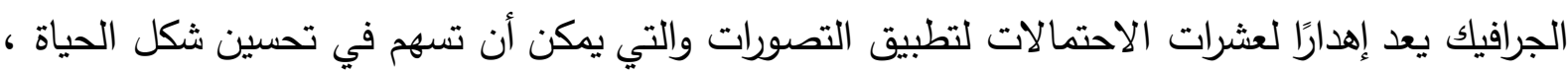

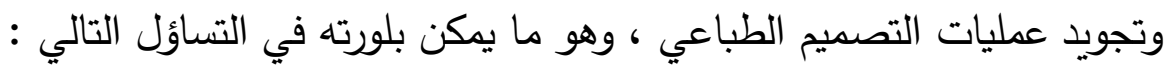

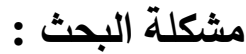
- -

- - مهدف البحث إلى دراسة الاحتمالات في ضوء الاعتبارات الجرافيكية لتحقيق التفاعل الجيد بين

التصميم والواقع والمتلقي بما يضمن سهولة قراءة التصميمات ومن ثم الاستجابة لمضمونها.

- التأكيد علي وعي المصدم وقدرته وتفهمه لعملية التصميم الطباعي وأساليب التطبيق لها. 
- - المنهج التجريبي : من خلال التتاول المبتكر في توظيف التصميمات الطباعية بواسطة برامج

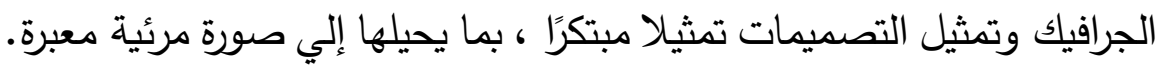

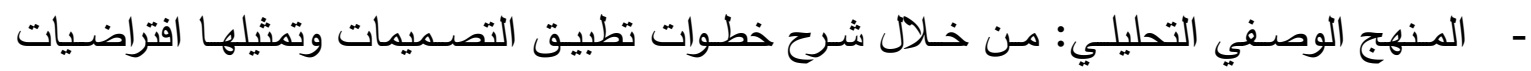

بأثكال متنوعة ، اضافة إلى شرح وتوصيف الأعمال من عدة جوانب .

الفكرة التثكيلية للبحث والحدود :

تقوم التجربـة أساسـا على تطبيق التصـيمات الطباعيـة باعتبارهـا جزه مـن جماليـات المكان وتوظيفها بصور متتوعة كأقمشة مفروشات - ستائر - معلقات .. الخ ، بهدف إظهار الأبعاد الجمالية والوظيفية للتصميمات الطباعية وإثراء البيئة المحيطة بالإنسان. - تقتصر التجربة توظيف التصميمات الطباعية بصور متتوعة .

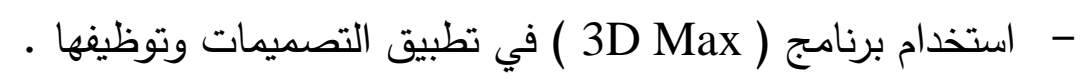

التعريف بيرنامج ( 3D Max )

واحد من أقوي برامج الجرافيك " في الرسم الثثلثي البعد على الإطلاق بما له من إمكانات خارقة

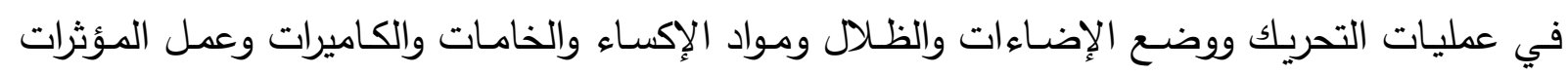

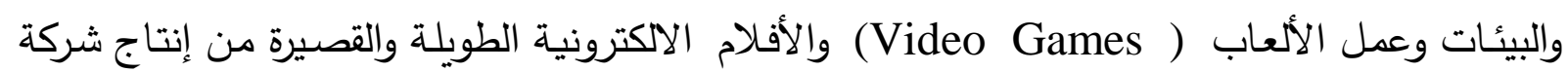

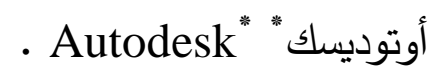

تطبيق التصميمات وتوظيفها :

تعد أقشــة المفروشـات والستائر والمعلقـات أحد أهم المكونـات التـي تعبر تعبيـرا صـامتا عن شخصية المكان ، حيث يتطلب بناء الديكور في النمط الحديث للمنازل والمكاتب إعداد مخطط لهيئة

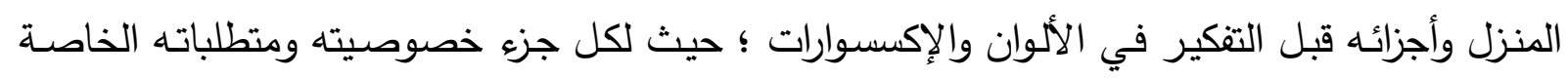

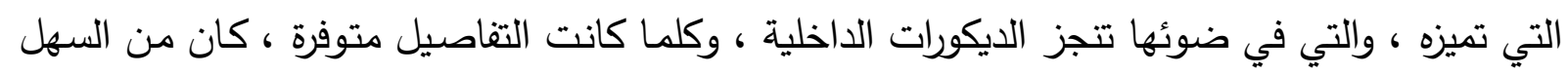
تحديد الثكل الذي سيكون عليه المنزل ، وهو ما يجنبنا الوقوع في العديد من الأخطاء .

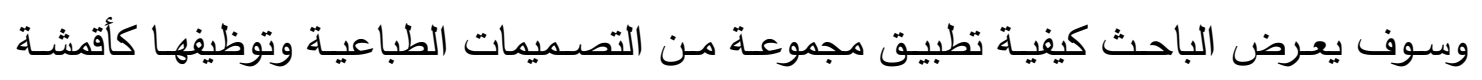

مفروشات متتوعة وستائر ومعلقات من خلال خاصية الإكساء الموجودة في برنامج ( 3D Max ) من خلا إكساء كل قطعة على حده ومن ثم مزج الأجزاء مع بعضها بالأمر Attach ؛ نظرا لتعدد الأجزاء

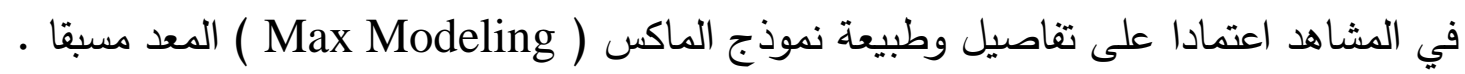
خطوات الإكساء :

لتطبيق لابد من وجود نموذج يتم لإكسائه مسبقا ، كما ينبغي أن يكون التصميم أو التصميمات المراد الإكساء بها في صورة ملف في Material Map كما في الثكلين التاليين : 
• برامج الجرافيك مثل ( 3D Max - AutoCad - Cinema 4D Studio - Maya ) وغيرها .

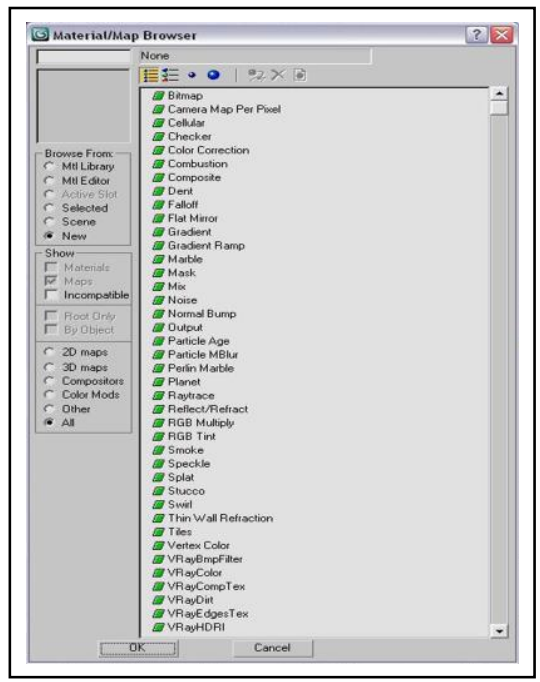
.. شركة أوتوديسك Autodesk واحدة من كبرى شركات إنتاج برامج الجرافيك في العالم .

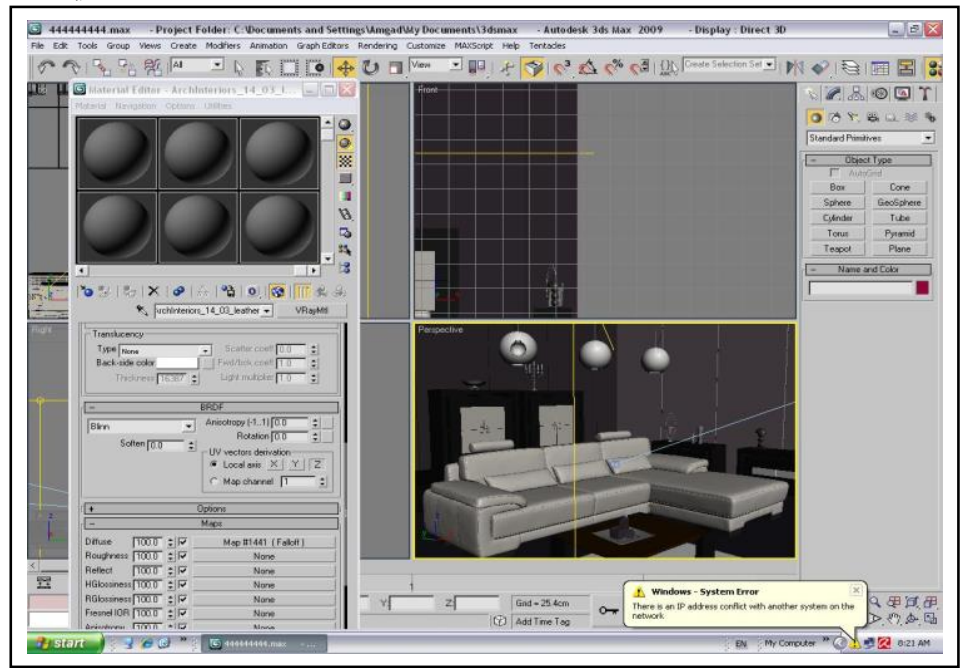

- - ويتم إدراج التصميمات المراد الإكساء بها من Bitmap أول خيارات القائمة السابقة . - ـ وقد قام الباحث بعد اعداد التصميمات باختيار ثلاث تصميمات لشرح لإكساء بها ، كما في الأشكال التالية :
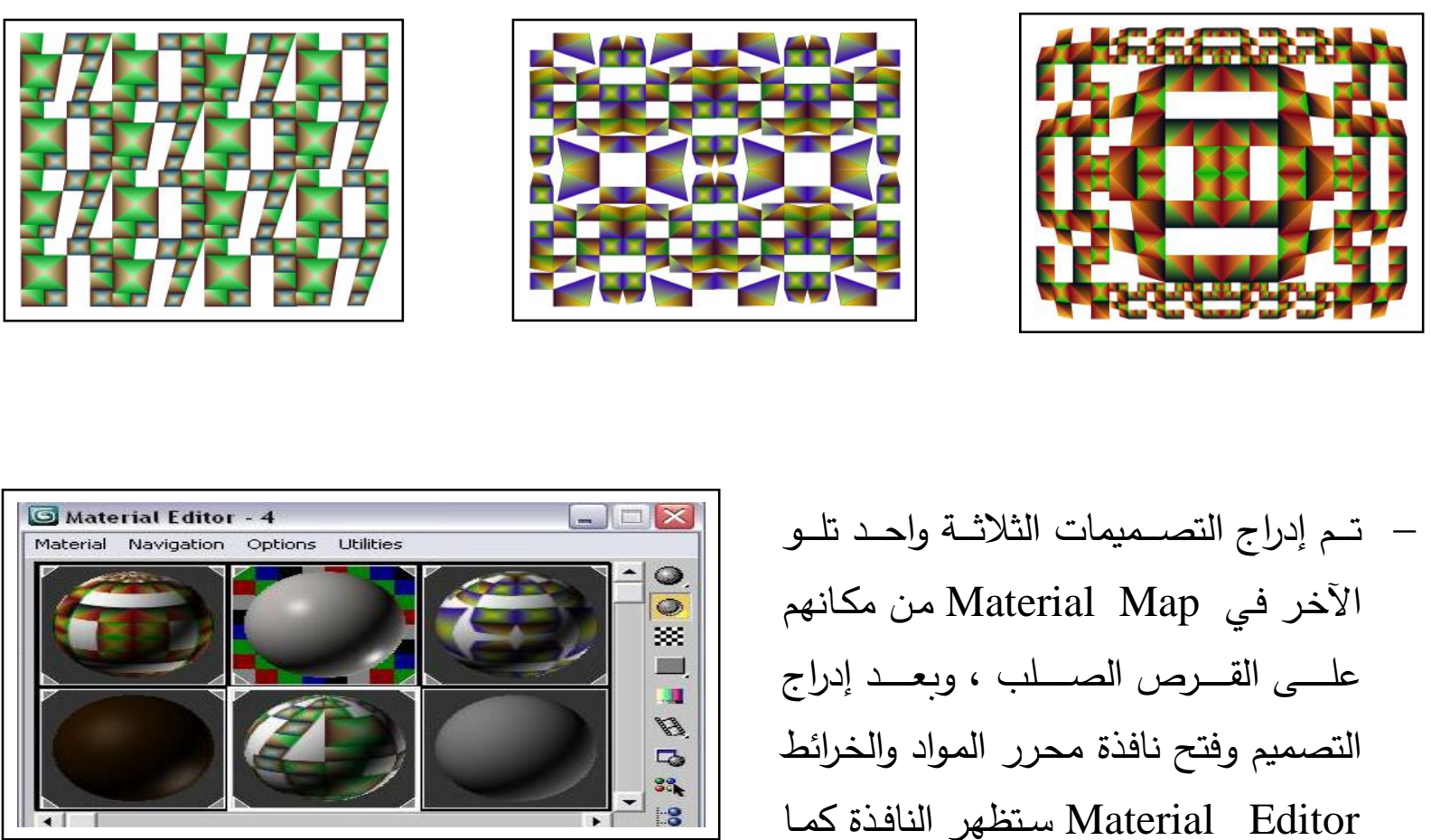

- تــم إدراج التصـميمات الثلاثـة واحـد تلـو الآخر في Material Map من مكانهم علـى القــرص الصــلب ، وبعـــــ إدراج التصميم وفتح نافذة محرر المواد والخرائط Material Editor

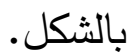


- بعد ذلك يتم اختيار الجزء المراد تطبيق التصميم عليه وتحديده ، وبعدها يتم الضغط على زر تعيين الخامة على الاختيار Assign Material to Selection كما في النافنتين التاليتين :
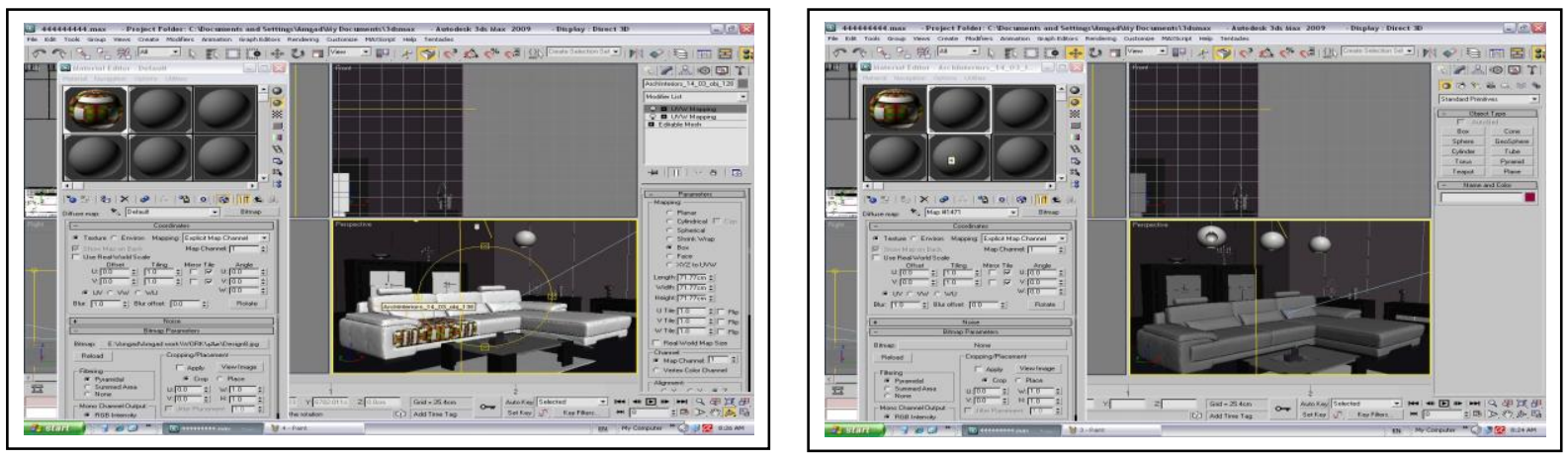

- - يتم تكرار الخطوة السابقة واختيار الجزء التالي مرة بعد مرة وفي كل مرة تطبيق التصميم عليه

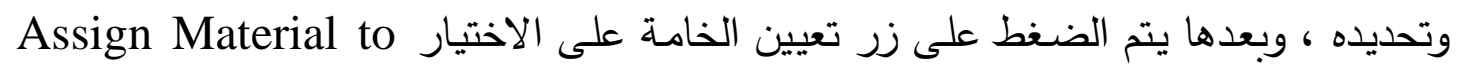
Selection

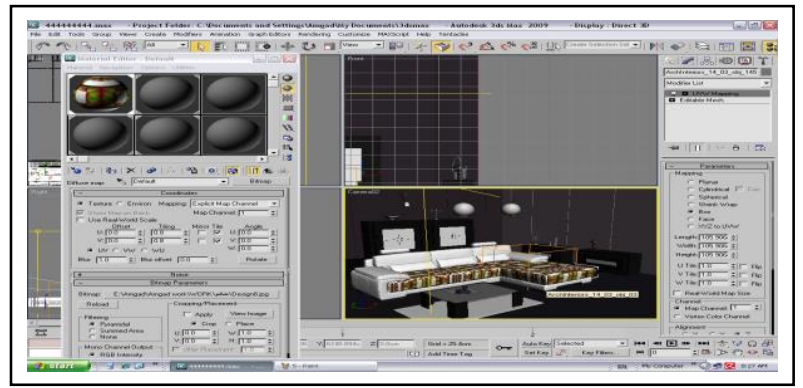

Material Editor بعد إدراج التصميمات المراد الإكساء بها وفتح نافذة محرر المواد والخرائط -

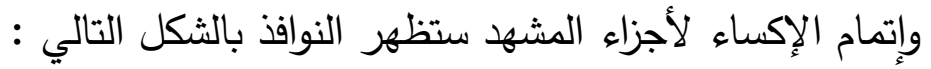
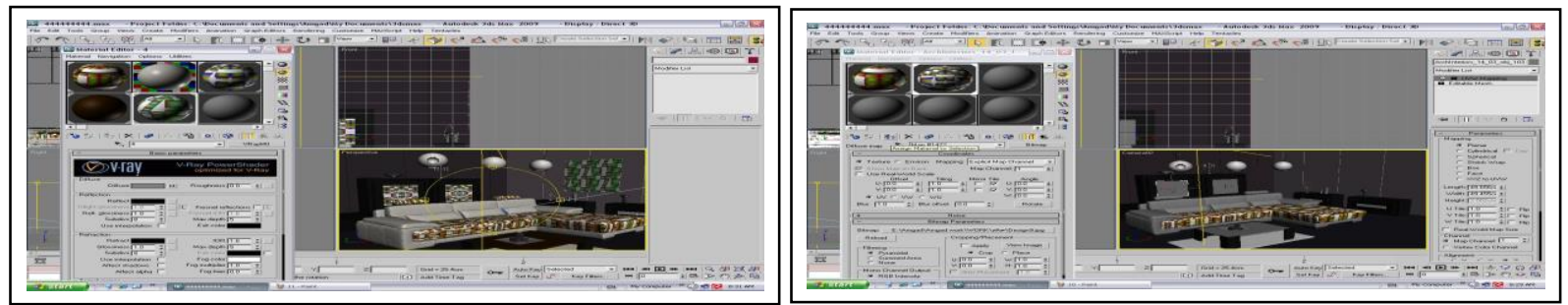
- ميمكن مشاهدة المنظر العام قبل أظظهر يمكن عرضه من خلال نافذة العرض Perspective .

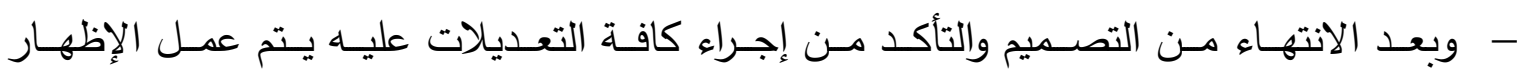

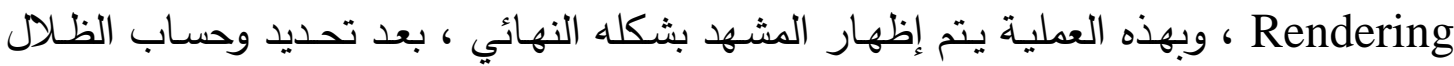
والانعكاسات والانكسارات والمؤثرات وغيرها ، بالإضافة إلى تتعيم حواف العناصر وكل ما يلزم

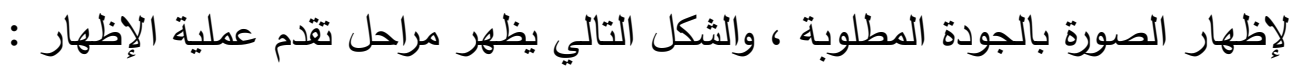
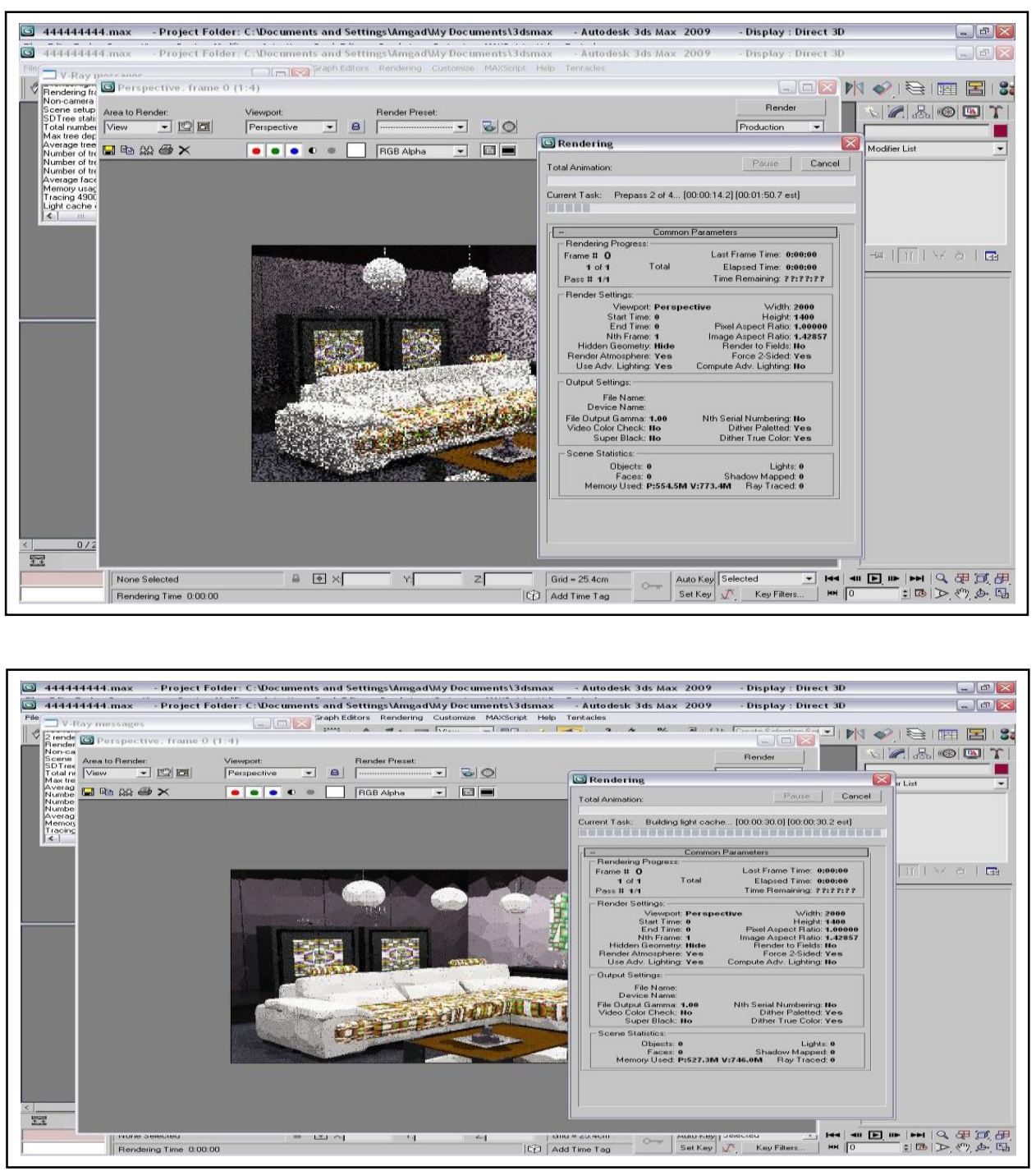

- بعد الانتهاء من عملية الإظهار للمشهد يظهر بثكله النهائي كما في النافذة التالية :

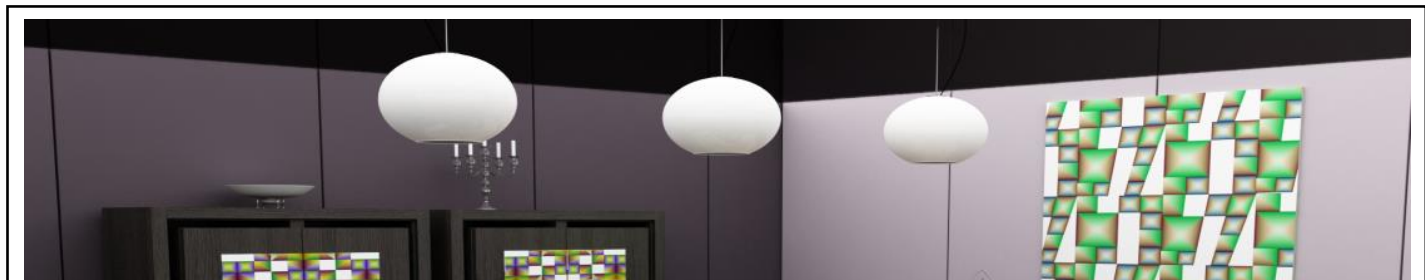


وبعد أن قدم الباحث في الجزء السـابق شرحا مفصـلا لخطوات تطبيق وتوظيف التصميمات

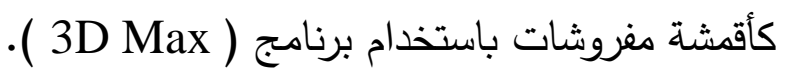

سوف يتـاول الباحث في الجزء التالي تطبيق وتوظيف بـاقي التصميمات الطباعيـة كأقمشة مفروشـات متتوعـة ، باستخدام برنـامج ( 3D Max ) ؛ بهدف إظهار الأبعاد الجماليـة والوظيفيـة

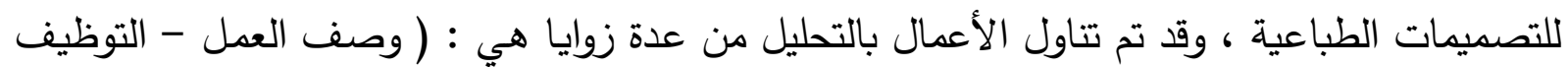

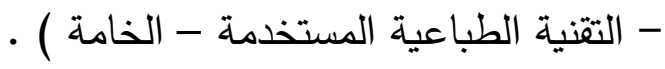

\begin{tabular}{|c|c|c|c|}
\hline العمل الثالث & العمل الثاني & العمل الأول & تحليل العمل \\
\hline انتريه مكتب & غرفة نوم & غرفة معيشة & وصــف العمل \\
\hline أقرشة تتجيد & مغرش سرير & أقمشة تتجيد - أرضيات & نـــوع التوظيــف \\
\hline طباعة رقية & طباعة رقمية & طباعة رقمية & التقنية الطباعية المستخدمة \\
\hline جلوسي Gloosy & جلوسي Gloosy & جلوسي Gloosy & الخــــامة \\
\hline & 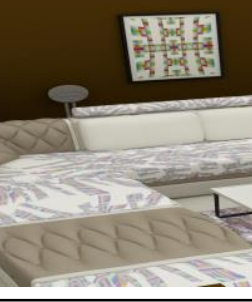 & sinse & العمل الأول \\
\hline
\end{tabular}


العمل الثاني
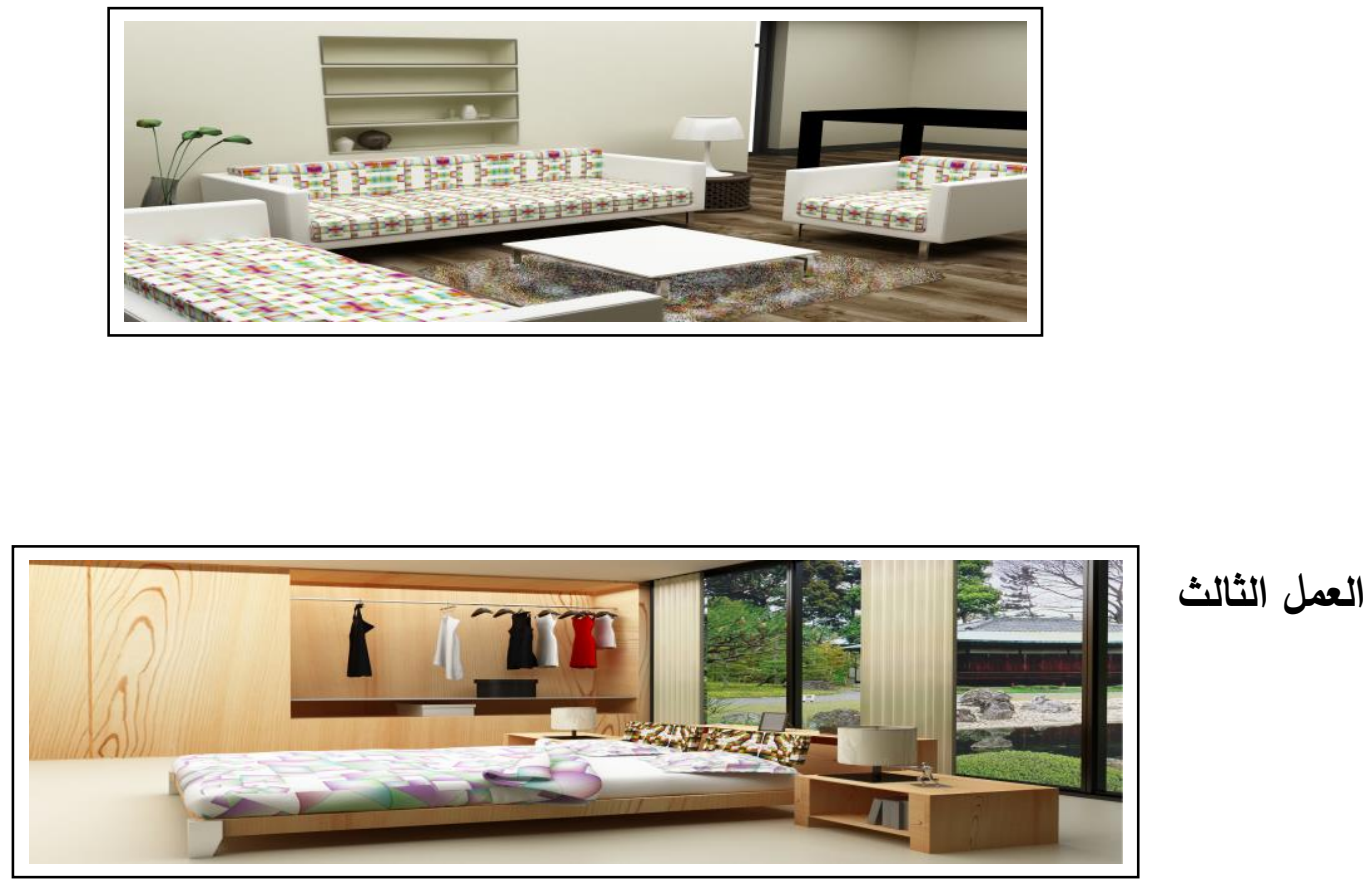

\begin{tabular}{|c|c|c|c|}
\hline العمل السادس & العمل الخامس & العمل الرابع & رقم العمل \\
\hline جزء من جناح بنندق & غرفة نوم & كرسي صالون & وصــف العـمل \\
\hline مفرش سرير تتجيد وستائر & مفرش سرير وأكياس وسادة & أقشة تتجيد & نــوع التوظيــف \\
\hline طباعة رقمية & طباعة رقمية & طباعة رقمية & التقنية الطباعية المستخدمة \\
\hline جلوسي Gloosy & جلوسي Gloosy & جلوسي Gloosy & الخـــــامة \\
\hline
\end{tabular}




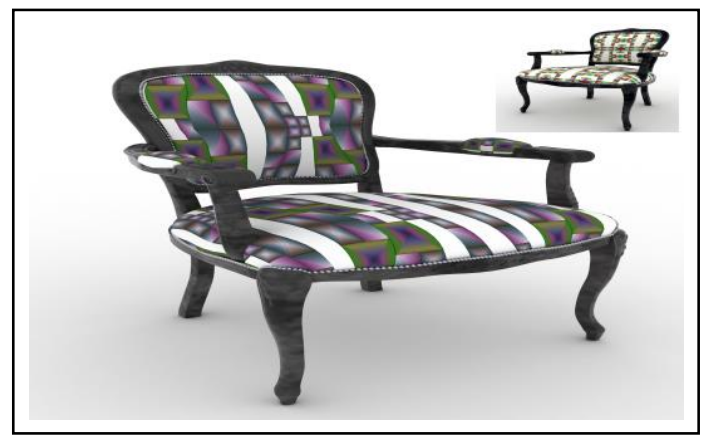

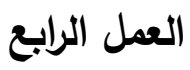

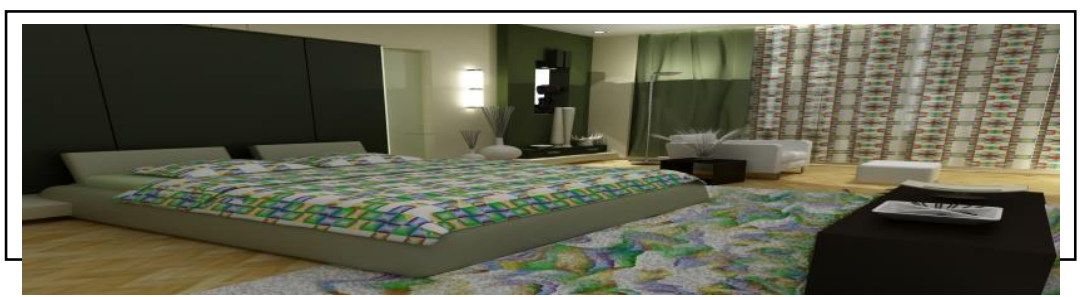

العمل الخامس

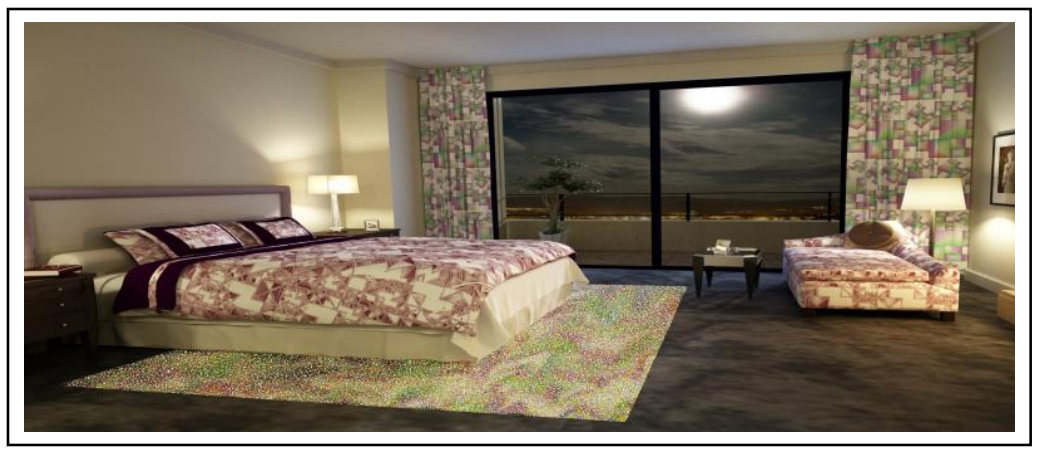

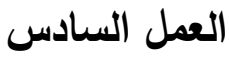

- استخدام برنـامج ( 3D Max ) في أسهم بثكل فعـال في إدراك وتفعيل الواقـع الافتراضـي

للتصميمات الطباعية للبحث الحالي . لإن

- استخدام برنامج ( 3D Max ) في أسهم بشكل فعال في دراسة الاحتمالات في ضوء الاعتبارات الجرافيكية للتصميمات الطباعية بما يضمن سهولة قراءة التصميمات ومن ثم الاستجابة لمضمونها 
- استخدام برنامج ( 3D Max ) أسهم بشكل فعال في زيادة وعي المصمم وقدرته وتفهمه لعملية التصديم الطباعي وأساليب التطبيق لها في البحث الحالي.

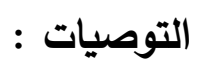

- التوسع في تدريس برامج الجرافيك المختلفة واستخداماتها في اعداد التصميمات الطباعية وتطبيقها

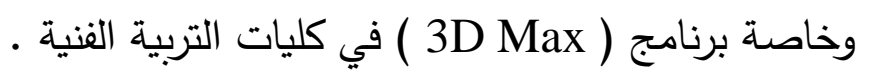

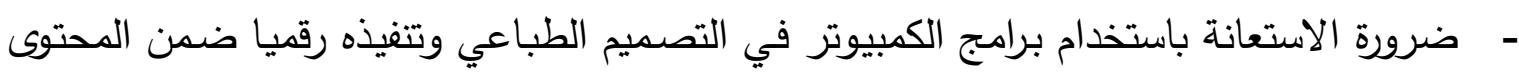

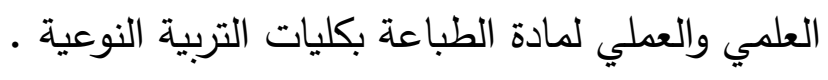

1- أحمد وحيد مصطفى : التطبيقات الجر افيكية للحاسبات ، القاهرة ، روز اليوسف ، 2000 .

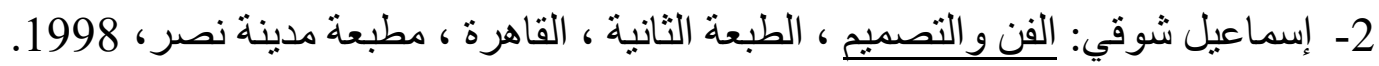

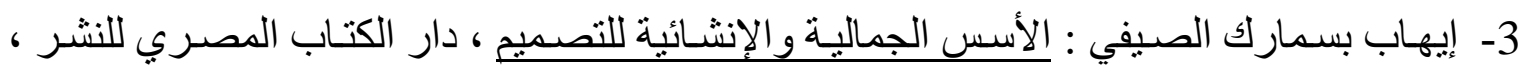

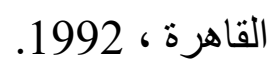

4- سـامي حسين عبد البـاقي : استخدام الكمبيوتر في برمجـة الإمكانـات البنائيـة و الجماليـة لعمليـة

التصميم النسجى للأقشة للمتطلبات العصرية للمجتمع، رسالة دكتور اهـئ ، كلية الفنون التطبيقية ،

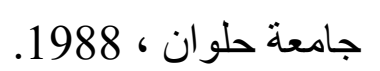

5- مصطفي فريد الرزاز : أسس التصميم بين و اقعها البنائي وبعدها الإدر اكي ، مطبعة جامعة حلوان

$$
\text { ، القاهرة ، } 1981 .
$$

6- King Slake, Richard : An Introducing Course Computer Graphics, New York, 1991.

7- Terger Casper \& Srteven Elliot : Computer Design Basic Concepts Charles and Merril Co. , U.S.A , 1995 .

8- Thompson, Nill : Art and Computers - Computer, U.K. ,1997. 